\title{
Carbapenems as inhibitors of OXA-13, a novel, integron-encoded $\beta$-lactamase in Pseudomonas aeruginosa
}

\author{
P. Mugnier, ${ }^{1} \dagger$ I. Podglajen, ${ }^{1} \neq$ F. W. Goldstein ${ }^{2}$ and E. Collatz ${ }^{1}$ \\ Author for correspondence: E. Collatz. Tel: +331432928 65. Fax: +33143256812. \\ e-mail: collatz@ccr.jussieu.fr
}

1 Laboratoire de Recherche Moléculaire sur les Antibiotiques, Université Paris VI, 15 rue de l'Ecole de Médecine, 75270 Paris Cedex 06, France

2 Service de Microbiologie Médicale, Fondation Hópital Saint-Joseph, 7 rue Pierre-Larousse, 75674

Paris Cedex 14, France

\begin{abstract}
A clinical Pseudomonas aeruginosa strain, PAe391, was found to be resistant to a number of antibiotics including ticarcillin, piperacillin, cefsulodin and amikacin, and a disk diffusion assay showed evidence of pronounced synergy between imipenem and various $\beta$-lactam antibiotics. Cloning and nucleotide sequence analysis revealed the dicistronic arrangement of an $\operatorname{aac}\left(6^{\prime}\right)-1 / \mathrm{b}$ variant and a novel bla $a_{\text {oxA }}$-type gene between the intI and qacE $\Delta 1$ genes typical of integrons. In PAe391, this integron was apparently chromosome-borne. The $\beta$ lactamase, named OXA-13, displayed nine amino acid changes with respect to OXA-10: I in position 10 of OXA-10 to T (110T), G20S, D55N, N73S, T107S, Y174F, E229G, S245N and E259A. OXA-13 ( $\mathrm{pl}_{\mathrm{app}}=8.0$ ) showed poor catalytic activity against penicillins as well as cephalosporins, but was efficient in hydrolysing some penicillinase-resistant $\beta$-lactams, such as cefotaxime and aztreonam. It was efficiently inhibited by imipenem $\left(K_{\text {iapp }}=11 \mathrm{nM}\right)$, and formed a stable complex. While the $K_{\text {iapp }}$ value of meropenem was similar (16 $\mathrm{nM}$ ), the corresponding complex was less stable.
\end{abstract}

Keywords: $\beta$-lactam resistance, oxacillinase, carbapenem, integron, Pseudomonas aeruginosa

\section{INTRODUCTION}

Production of $\beta$-lactamases is the most frequent cause of resistance to $\beta$-lactam antibiotics in Gram-negative bacteria (Livermore, 1995). Pseudomonas aeruginosa produces a chromosome-encoded cephalosporinase which renders it naturally resistant to ampicillin and cephalothin. This may be one reason why secondary (or 'acquired') $\beta$-lactamases are more rarely observed in this species than in the Enterobacteriaceae. In $P$. aeruginos $a$, secondary $\beta$-lactamases are mostly plasmidencoded CARB-, PSE- or OXA-, rather than TEM- or SHV-type enzymes. As a result, the $\beta$-lactam susceptibility of strains producing secondary $\beta$-lactamases is not consistently restored by the commercially available $\beta$-lactamase inhibitors, such as clavulanic acid, sulbactam and tazobactam, which are potent inhibitors of

†Present address: Department of Biosciences, University of Kent, Canterbury, Kent CT2 7NJ, UK.

¥Present address: Tufts University, Center for Adaptation Genetics and Drug Resistance, 136 Harrison Avenue, Boston, MA 02111, USA.

The GenBank/EMBLDDBJ accession number for the sequence reported in this paper is U59183. group $2 \mathrm{~b}$ and $2 \mathrm{c}$, but not of group $2 \mathrm{~d}$ enzymes (Bush et al., 1995).

Carbenicillinase and oxacillinase genes are frequently carried by integrons (Lafond et al., 1989; Stokes \& Hall, 1989; Hall \& Collis, 1995) or related genetic structures, which explains why the $\beta$-lactam resistance is associated with resistance to various other antibiotics, including aminoglycosides. Indeed, several genes encoding $\beta$ lactam, aminoglycoside, chloramphenicol or trimethoprim resistance may be inserted in the form of cassettes into an ancestral integron, or one that contains one or more resistance gene cassettes, by site-specific integrasedependent recombination (Grinsted et al., 1990; Stokes $\&$ Hall, 1989). The sequential integration of cassettes may then yield a great variety of resistance gene arrangements (Lafond et al., 1989; Lévesque et al., 1995).

Here we describe an oxacillinase variant, OXA-13 (formerly called OXA-12; Mugnier et al., 1994), which is efficiently inhibited by imipenem. This $\beta$-lactamase was produced by a clinical $P$. aeruginosa strain, in association with an aminoglycoside $6^{\prime}-N$-acetyltransferase variant, $\mathrm{AAC}\left(6^{\prime}\right)-\mathrm{Ib}_{10}$. Both the $a a c\left(6^{\prime}\right)-I b$ and the 
$b l a_{\text {Ox A }}$ genes were localized, in that order, between the $5^{\prime}$ - and the $3^{\prime}$-conserved segments of a sull-type integron.

\section{METHODS}

Bacterial strains, plasmids and growth conditions. The bacterial strains and plasmids used are listed in Table 1. $P$. aeruginosa PAe391 was isolated in 1990 at the Saint-Joseph Hospital, Paris, from the sputum of a patient suffering from chronic bronchitis. It was resistant to several anti-Pseudomonas $\beta$-lactam antibiotics such as ticarcillin, piperacillin and cefsulodin, whether combined with commercially available $\beta$ lactamase inhibitors or not, and also to gentamicin, netilmicin, tobramycin, amikacin, isepamicin, sulfonamides and mercuric ions. Bacterial strains were grown in Mueller-Hinton $(\mathrm{MH})$ or Brain Heart Infusion (BHI) media at $37^{\circ} \mathrm{C}$.

Determination of MICs. This was done on $\mathrm{MH}$ agar containing serially twofold-diluted antibiotics. Inocula were adjusted to approximately $10^{4}$ c.f.u. per spot and applied with a Steerstype inoculator. Plates were incubated at $37^{\circ} \mathrm{C}$ for $18 \mathrm{~h}$. The MICs of $\beta$-lactam antibiotics were determined alone or in the presence of clavulanic acid or tazobactam at $4 \mu \mathrm{g} \mathrm{ml}^{-1}$. Imipenem was also used as an inhibitor, at $0.03 \mu \mathrm{g} \mathrm{ml}^{-1}$ with Escherichia coli and $0.25 \mu \mathrm{g} \mathrm{ml}^{-1}$ with $P$. aeruginosa strains, i.e., at one-quarter of its respective MIC. MICs were determined twice, with identical results.

Antimicrobial agents were provided as follows: ampicillin, aztreonam and oxacillin, Bristol Myers Squibb; ceftazidime and cephaloridine, Glaxo Group Research; cefotaxime, Hoechst Roussel Pharmaceuticals; piperacillin and tazobac- tam, Wyeth-Lederle Laboratories; imipenem, Merck Sharp and Dohme; cefoperazone, Pfizer Laboratories; amoxicillin, clavulanic acid and ticarcillin, SmithKline Beecham; benzylpenicillin, Spécia Rhône-Poulenc Rorer Laboratories; cefsulodin, Takeda Laboratories; meropenem, Zeneca Pharmaceuticals.

Plasmid isolation, conjugation, cloning and transformation experiments. Several methods were used to extract plasmid DNA from PAe391 (Kado \& Liu, 1981; Takahashi \& Nagano, 1984) and recombinant plasmids from E. coli (Birnboim \& Doly, 1979). Attempts to transfer the $\beta$-lactam resistance marker into HB101 and PAO38R if (Table 1 ) were made, using mating procedures in solid and liquid media (Thompson, 1986; Robillard, 1990). Plasmids pNJR32 and pAZ309 were transferred to PAO38 from E. coli S17.1.

For the cloning of the $\beta$-lactam resistance marker, $1 \mu \mathrm{g}$ of total DNA from PAe391 was digested for $5 \mathrm{~h}$ with EcoRI and then ligated into the similarly digested vector pHSS6. E. coli HB101 was transformed with pHSS6 and its $\beta$-lactam-resistanceconferring derivatives, pAZ301 and pAZ304 (Table 1), by electroporation (Bio-Rad gene pulser). Transformants were selected on $\mathrm{MH}$ agar plates containing ampicillin $\left(100 \mu \mathrm{g} \mathrm{ml}^{-1}\right)$.

Preparation, purification and $\mathbf{N}$-terminal sequence analysis of OXA-13. Crude enzyme extracts were prepared from cultures grown at $37^{\circ} \mathrm{C}$ under vigorous shaking to an $\mathrm{OD}_{650}$ of approximately $0 \cdot 8$. Cells were harvested by centrifugation and disrupted by sonolysis in sodium phosphate buffer $(10 \mathrm{mM}, \mathrm{pH} \mathrm{7 \cdot 0)}$. Lysates were centrifuged for $15 \mathrm{~min}$ at $4000 \mathrm{~g}$ and then for $45 \mathrm{~min}$ at $100000 \mathrm{~g}$. The supernatants

Table 1. Bacterial strains and plasmids

\begin{tabular}{|c|c|c|c|}
\hline Strain or plasmid & Genotype or description & Resistance phenotype* & Reference or source \\
\hline \multicolumn{4}{|l|}{$\begin{array}{l}P . \text { aeruginosa } \\
\text { strains }\end{array}$} \\
\hline PAe391 & Clinical strain & Ti Im Ak Ge Su Hg & This study \\
\hline PAO38 & $\begin{array}{l}\beta \text {-lactam- and aminoglycoside-susceptible } \\
\text { strain }\end{array}$ & & $\begin{array}{l}\text { Pemberton \& Holloway } \\
\text { (1972) }\end{array}$ \\
\hline PAO38Rif & $\begin{array}{l}\text { High-level rifampin-resistant derivative of } \\
\text { PAO38 }\left(\mathrm{MIC}>500 \mu \mathrm{g} \mathrm{ml}^{-1}\right)\end{array}$ & $\mathrm{Ri}$ & This study \\
\hline \multicolumn{4}{|l|}{ E. coli strains } \\
\hline HB101 & 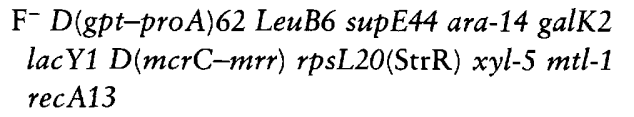 & Sm & New England Biolabs \\
\hline S17.1 & Pro $^{-}$Res $^{-} \mathrm{Mod}^{+}$ & $\mathrm{Tp} S \mathrm{~m}$ & Robillard (1990) \\
\hline \multicolumn{4}{|l|}{ Plasmids } \\
\hline pHSS6 & $2.3 \mathrm{~kb}$ plasmid vector & $\mathrm{Km}$ & Seifert et al. (1986) \\
\hline pAZ505 & pBR322 carrying $a a c\left(6^{\prime}\right)-I b$ & Ti Ak & $\begin{array}{l}\text { Tran Van Nhieu \& Collatz } \\
\text { (1987) }\end{array}$ \\
\hline pAZ301 & $\begin{array}{l}7.3 \mathrm{~kb} \text { EcoRI fragment obtained by digestion } \\
\text { of PAe391 total DNA, cloned into pHSS6 }\end{array}$ & $\mathrm{Km} \mathrm{Ti} \mathrm{Ak} \mathrm{Su}$ & This study \\
\hline pAZ304 & $\begin{array}{l}2.7 \mathrm{~kb} \text { BamHI-PstI fragment of pAZ301 cloned } \\
\text { into the BamHI-PstI site of pHSS6 }\end{array}$ & $\mathrm{Km} \mathrm{Ti} \mathrm{Ak}$ & This study \\
\hline pNJR32 & $28 \mathrm{~kb}$ E. coli-P. aeruginosa shuttle vector & Tc & Robillard (1990) \\
\hline pAZ309 & $\begin{array}{l}4.0 \mathrm{~kb} \text { HindIII fragment of pAZ301 cloned into } \\
\text { the HindIII site of pNJR32 }\end{array}$ & Tc Ti Ak & This study \\
\hline
\end{tabular}

* Resistance to: Ak, amikacin; Ge, gentamicin; Hg, mercuric ions; Im, imipenem; Km, kanamycin; Ri, rifampin; Sm, streptomycin; Su, sulfonamide; Tc, tetracycline; Ti, ticarcillin; Tp, trimethoprime. 

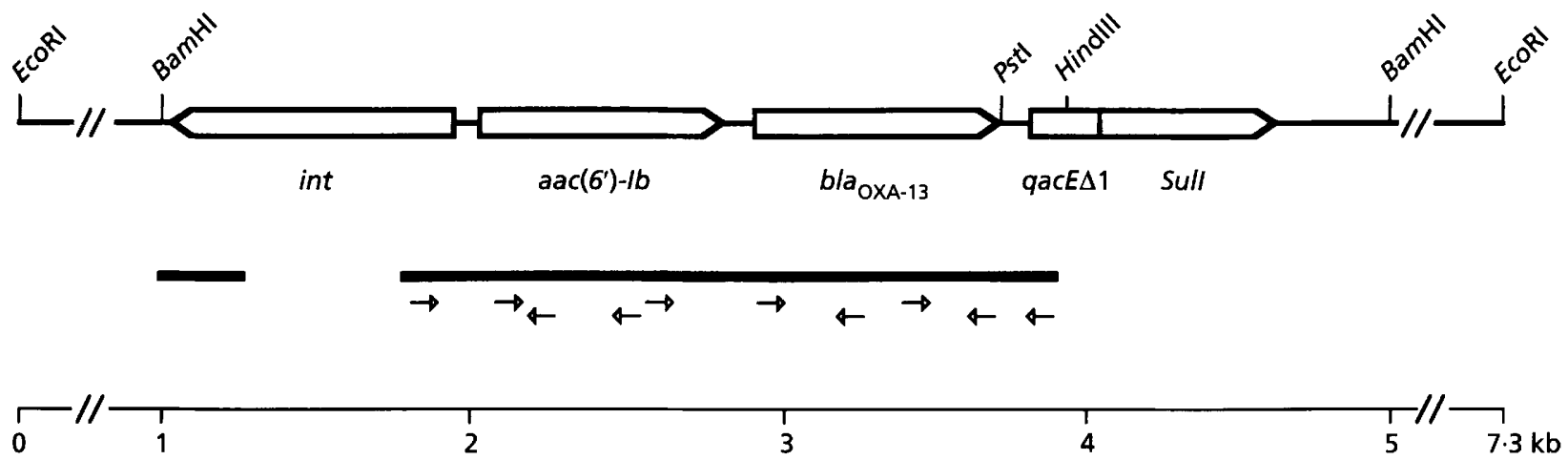

Fig. 1. Restriction map of the $\operatorname{aac}\left(6^{\prime}\right)-1 b_{10^{-}}$and bla $\mathrm{OXA}_{-13^{-}}$-encoding $7 \cdot 3 \mathrm{~kb}$ region of PAe391. The portion sequenced is indicated by the thick line; small arrows represent the newly synthesized primers used. The restriction endonuclease sites were determined on the isolated fragment (data not shown).

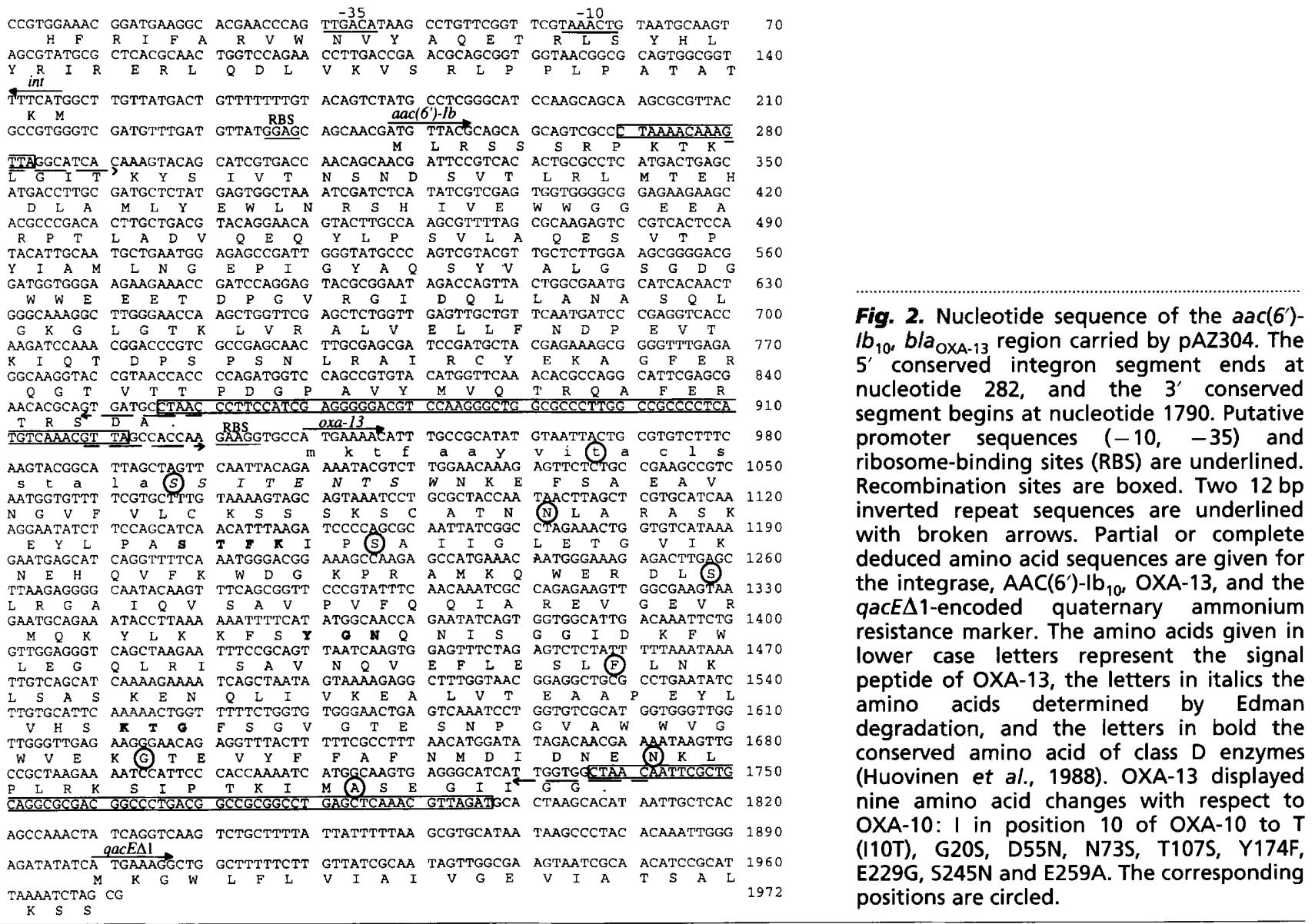

(S100) were used for isoelectric focusing experiments and for assaying the stability of $\beta$-lactamase: inhibitor complexes.

OXA-13 was partially purified from a crude extract of HB101(pAZ304) using the preparative isoelectric focusing cell Rotofor (Bio-Rad). The fraction containing the highest $\beta$ lactamase activity was used for the determination of kinetic parameters. This fraction was subjected to SDS-PAGE (Laemmli, 1970) and the $\beta$-lactamase concentration was estimated by comparative densitometry with BSA as standard. For N-terminal sequence analysis, OXA-13 was transferred to a PVDF membrane (Millipore), stained with Coomassie blue and cut out, and its $\mathrm{N}$-terminal amino acid sequence determined on a model 473 protein sequencer (Applied Biosystems). Phenylthiohydantoin derivatives of the eight $\mathrm{N}$ terminal amino acids were separated and identified by on-line reverse phase-HPLC with an RP-18 column (Brownlee Labs, Applied Biosystems). This analysis was carried out in the laboratory of L. Camoin (ICGM, Paris, France).

Isoelectric focusing. S100 preparations were analysed by isoelectric focusing using a mini IEF cell III (Bio-Rad) and a 
Table 2. MICs of $\beta$-lactam antibiotics and amikacin for PAe391 and transformants

\begin{tabular}{|c|c|c|c|c|c|c|}
\hline \multirow[t]{2}{*}{ Antibiotic } & \multirow[t]{2}{*}{ Inhibitor ${ }^{*}$} & \multicolumn{5}{|c|}{$\operatorname{MIC}\left(\mu \mathrm{g} \mathrm{ml}^{-1}\right)$} \\
\hline & & PAe391 & $\begin{array}{c}\text { PAO38 } \\
\text { (pAZ309) }\end{array}$ & $\begin{array}{c}\text { HB101 } \\
\text { (pAZ304) }\end{array}$ & $\begin{array}{c}\text { PAO38 } \\
\text { (pNJR32) }\end{array}$ & $\begin{array}{c}\text { HB101 } \\
\text { (pHSS6) }\end{array}$ \\
\hline \multirow[t]{3}{*}{ Amoxicillin } & - & $>512$ & $>512$ & $>512$ & $>512$ & 8 \\
\hline & $\mathrm{Cla}$ & $>512$ & $>512$ & 512 & $>512$ & 4 \\
\hline & Imi & $>512$ & $>512$ & 32 & $>512$ & 4 \\
\hline \multirow[t]{3}{*}{ Ticarcillin } & - & 128 & 256 & $>512$ & 8 & 4 \\
\hline & $\mathrm{Cla}$ & 64 & 256 & 256 & 16 & 2 \\
\hline & Imi & 8 & 64 & 16 & 64 & 2 \\
\hline \multirow[t]{2}{*}{ Piperacillin } & - & 32 & 32 & 64 & 2 & 1 \\
\hline & Taz & 32 & 32 & 32 & 2 & 1 \\
\hline Cefoperazone & - & 128 & 128 & 32 & 2 & $0 \cdot 12$ \\
\hline Cefotaxime & - & 8 & 16 & 2 & 8 & 0.06 \\
\hline \multirow[t]{3}{*}{ Ceftazidime } & - & 2 & 2 & 1 & 1 & $0 \cdot 12$ \\
\hline & $\mathrm{Cla}$ & 2 & 2 & $0 \cdot 12$ & 2 & $0 \cdot 12$ \\
\hline & Imi & 4 & 16 & $0 \cdot 12$ & 16 & $0 \cdot 12$ \\
\hline \multirow[t]{3}{*}{ Aztreonam } & - & 4 & 8 & 4 & 2 & $0 \cdot 12$ \\
\hline & $\mathrm{Cla}$ & 2 & 4 & $0 \cdot 25$ & 2 & $0 \cdot 06$ \\
\hline & Imi & 2 & 8 & $0 \cdot 12$ & 16 & 0.06 \\
\hline \multirow[t]{2}{*}{ Cefsulodin } & - & 16 & 32 & ND & 1 & ND \\
\hline & Imi & 2 & 16 & ND & 8 & ND \\
\hline \multirow[t]{2}{*}{ Meropenem } & - & $0 \cdot 5$ & 2 & 0.03 & 0.5 & 0.015 \\
\hline & Imi & $0 \cdot 12$ & 0.5 & $0 \cdot 015$ & 1 & $0 \cdot 015$ \\
\hline Imipenem & - & 4 & 1 & $0 \cdot 12$ & 1 & $0 \cdot 12$ \\
\hline Amikacin & - & 16 & 16 & 64 & 4 & 8 \\
\hline
\end{tabular}

ND, Not determined (natural low susceptibility to cefsulodin).

*Cla, clavulanic acid $\left(2 \mu \mathrm{g} \mathrm{ml}^{-1}\right)$; Imi, imipenem $\left(0.03 \mu \mathrm{g} \mathrm{ml}^{-1}\right.$ for E. coli strains and $0.25 \mu \mathrm{g} \mathrm{ml}^{-1}$ for $P$. aeruginosa strains); Taz, tazobactam $\left(4 \mu \mathrm{g} \mathrm{m}^{-1}\right) ;-$, none.

gradient made up of one-half polyampholytes (Serva) of $\mathrm{pH}$ range 2-11 and one-half of $\mathrm{pH}$ range $6-9$. Extracts of OXA10-, SHV-1- and SHV-5-producing strains were used as standards for pIs of $6 \cdot 1,7 \cdot 6$ and $8 \cdot 2$, respectively. $\beta$-Lactamases were revealed by overlay with nitrocefin $\left(0 \cdot 1 \mathrm{mg} \mathrm{ml}^{-1}\right)$ in phosphate buffer $(50 \mathrm{mM}, \mathrm{pH} 7 \cdot 0)$.

Enzyme assays. Kinetic parameters were determined spectrophotometrically in phosphate buffer $(50 \mathrm{mM}, \mathrm{pH} 7 \cdot 0)$ at $30^{\circ} \mathrm{C}$ with a model $550 S$ double beam spectrophotometer (Perkin Elmer). Relative $V_{\max }$ and $K_{\mathrm{m}}$ values of substrates were determined by computerized linear regression analysis of Eadie-Hofstee plots. $K_{\text {iap }}$ values of inhibitors were deduced from Dixon plots. When burst or lag phenomena were observed during the initial phase of hydrolysis, the subsequent steady state rates were used for the determination of the kinetic constants.

Estimation of the stability of OXA-13:inhibitor complexes. An S100 sample of OXA-13 was incubated for $30 \mathrm{~min}$ at room temperature in phosphate buffer $(50 \mathrm{mM}, \mathrm{pH} 7.0)$ in the presence of $70 \mu \mathrm{M}$ imipenem or meropenem. Free inhibitor was separated from the OXA-13:inhibitor complex during isoelectric focusing (see above), or by gel filtration on a $1 \times 30 \mathrm{~cm}$ Trisacryl $/$ GF05 column (IBF-LKB), equilibrated with phosphate buffer $(50 \mathrm{mM}, \mathrm{pH} 7 \cdot 0)$ at $4{ }^{\circ} \mathrm{C}$. The column fraction with the highest absorbance at $280 \mathrm{~nm}$ was used for the subsequent steps. A second S100 sample of identical volume and concentration, incubated in the absence of inhibitor, was processed in exactly the same way as a control. The experimental and control column fractions of practically identical $\mathrm{OD}_{280}$ (less than $8 \%$ variation) were diluted 18 -fold in phosphate buffer $(50 \mathrm{mM}, \mathrm{pH} 7 \cdot 0)$ and kept at $30^{\circ} \mathrm{C}$. The enzymic activity was determined in $900 \mu \mathrm{l}$ aliquots at regular time intervals with cephaloridine $(100 \mu \mathrm{M})$ as the substrate. The relative hydrolytic activity in the extract preincubated with inhibitor was expressed with respect to the activity in the control, which was set at 1 at each time point. The stability of the complexes was estimated from two independent experiments.

DNA sequencing. The $3.0 \mathrm{~kb} B a m \mathrm{HI}-H$ indIII fragment of pAZ301 (Fig. 1) was cloned into the BamHI-HindIII site of phages M13mp18 and M13mp19. Two clones of each singlestranded recombinant phage were partially sequenced by the dideoxy chain-termination method using the T7 sequencing kit (Pharmacia). The universal primer and custom synthesized primers were used. When putative compressions were observed after the sequencing of one strand, the sequence of the complementary strand was determined. Since compressions are frequently encountered during DNA sequencing of integron-associated recombination sites (Hall et al., 1991), the nucleotide sequences from positions 850 to 930 and 1730 to 
1800 (Fig. 2) were determined on both strands using deazanucleotides and a thermal cycle DNA sequencing system ( $f m o l$ DNA sequencing system, Promega).

\section{RESULTS}

The clinical strain PAe391 was moderately resistant to ticarcillin, piperacillin, cefoperazone and cefsulodin, and showed reduced susceptibility to aztreonam and imipenem (Table 2). It was also resistant to amikacin, tobramycin, isepamicin, netilmicin and gentamicin (data not shown), compatible with the production of an AAC $\left(6^{\prime}\right)$-I and an AAC(3)-II (Shaw et al., 1993), and to sulfonamides (Table 1). PAe391 was peculiar in that it appeared susceptible to the synergistic activity of imipenem on one hand, and ticarcillin, cefsulodin, aztreonam or meropenem on the other, when tested in a standard disk diffusion assay (for cefsulodin and meropenem, see Fig. 3).

\section{Transfer and cloning of the resistance genes of PAe391}

Despite the use of two techniques and repeated attempts, no resistance marker was found to be transferable by conjugation, either to $P$. aeruginosa PAO38Rif or to $E$. coli HB101. No plasmid was detected in PAe391, even when techniques appropriate for the preparation of large plasmids $(\geqslant 100 \mathrm{~kb}$ ) were used.

Expression of $\beta$-lactam resistance was observed in E. coli HB101 after transformation with recombinant plasmids which were obtained by cloning of apparently chromosomal, $7.3,2.7$ and $4 \mathrm{~kb}$ fragments from PAe391 into pHSS6, yielding pAZ301 and pAZ304, and into pNJR32, yielding pAZ309, respectively (Table 1). Plasmid pAZ301 coded for $\beta$-lactam, amikacin and sulfonamide resistance, while pAZ304 and pAZ309 coded for $\beta$ lactam and aminoglycoside resistance only.

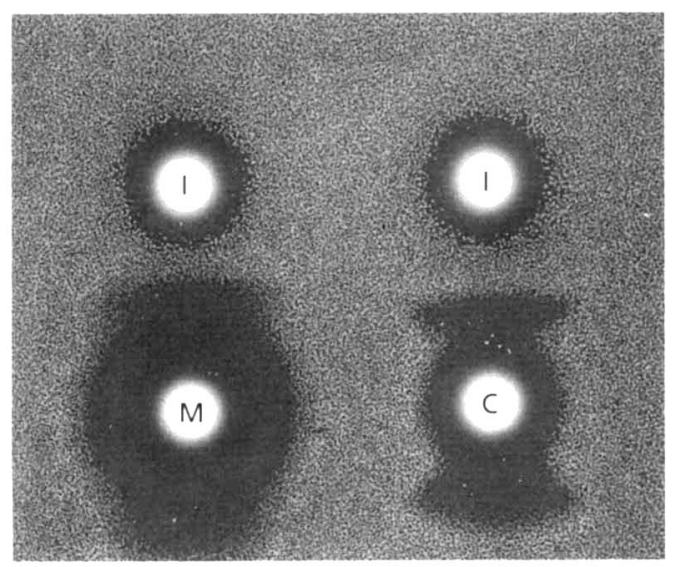

Fig. 3. Disk diffusion assay of PAe391 with imipenem (I), meropenem (M) and cefsulodin (C). The extensions of the circular zones of growth inhibition around $M$ and $C$ are indicative of enzyme inhibition by imipenem.

\section{$\beta$-Lactam resistance phenotypes}

As shown in Table 2, the $\beta$-lactam resistance levels of PAe391 and PAO38(pAZ309) were almost identical and overall very similar to those of E. coli HB101(pAZ304). The increases in MICs for the resistant transformants, when compared to their homologues carrying the cloning vector only, were obvious with ticarcillin, piperacillin and cefoperazone, and more subtle with aztreonam, cefotaxime and ceftazidime. The increases observed with these two groups of antibiotics were more pronounced in E. coli. They ranged, respectively, from 16- to 64-, and 2- to 4-fold for $P$. aeruginosa, and from 64- to 256-, and 8- to 32-fold for E. coli. The MIC of cefsulodin increased 32-fold for $P$. aeruginosa.

Clavulanic acid, and even more so imipenem, when used in association with other $\beta$-lactam antibiotics against the resistant transformants, restored various degrees of the $\beta$-lactam susceptibility that was displayed by the isogenic recipients. This phenomenon was somewhat masked in $P$. aeruginosa, particularly in PAO38(pAZ309), due to the well-known inducibility, by imipenem, of the chromosome-encoded cephalosporinase in this species (Livermore \& Yang, 1987). Surprisingly, and as observed in Fig. 3, there was also some synergistic effect between the two carbapenems, meropenem and imipenem, which was not masked in $P$. aeruginosa (Table 2), most likely because meropenem is not hydrolysed by the chromosomal enzyme, even after induction (Livermore, 1991).

The decreased susceptibility of PAe391 to imipenem was attributed to the decrease in production of an outermembrane protein of approximately $45 \mathrm{kDa}$ (Fig. 4), possibly OprD2 (Trias \& Nikaido, 1990).

\section{Identification and sequence determination of the $\beta$-lactam and aminoglycoside resistance genes of PAe391}

The nucleotide sequence of a $1972 \mathrm{bp}$ portion of the $3 \mathrm{~kb}$ BamHI-HindIII fragment of pAZ301 was determined (Figs 1,2). Analysis of the nucleotide and deduced amino acid sequences revealed the presence of two resistance genes in the same orientation, encoding an aminoglycoside $6^{\prime}-N$-acetyltransferase and an oxacillinase. Both genes were carried by an integron-related structure (Stokes \& Hall, 1989). The sequenced portion included at its extremities the $5^{\prime}$ conserved integron segment of $\operatorname{Tn} 21$ (nucleotides 1-282), encoding the integrase IntI (Ouellette \& Roy, 1987), a central section containing the two antibiotic resistance genes, and the 3 conserved segment (nucleotides 1791-1972) containing part of the qacE 1 gene (Paulsen et al., 1993).

Three recombination site sequences, also called $59 \mathrm{bp}$ elements (Cameron et al., 1986; Hall et al., 1991), hot spots (hs, Schmidt et al., 1989) or recombination hot spots (RHS, Francia et al., 1993), were found (Fig. 2). The hs 2 sequence was typical of the $3^{\prime}$ extremity of the $5^{\prime}$ conserved segment. The 67 bp sequence downstream 


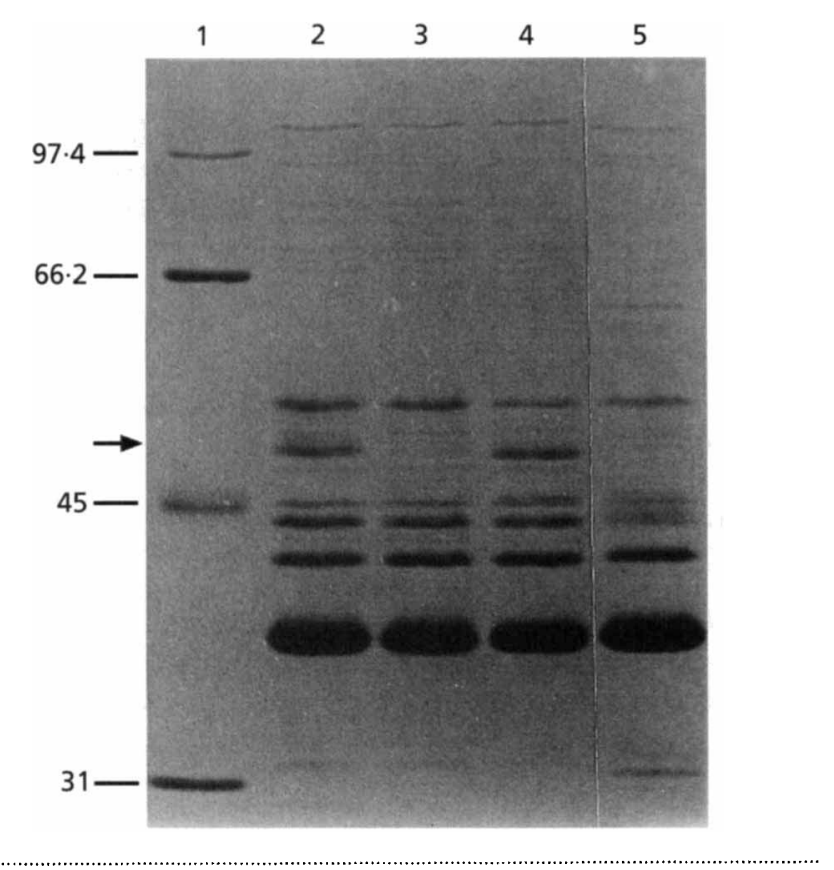

Fig. 4. Outer-membrane protein (OMP) profiles of $P$. aeruginosa strains. OMPs were prepared as described by Lee et al. (1992) but stained with Coomassie blue. Lanes: 2, PAe MDK1395-S (MIC of imipenem: $2 \mu \mathrm{g} \mathrm{ml}^{-1}$ ); 3, PAe MDK1395-R (MIC of imipenem: $32 \mu \mathrm{g} \mathrm{ml}^{-1}$ ) (for a description of the two PAe strains labelled MDK, see Zhou et al., 1993); 4, PAe191 (clinical isolate; MIC of imipenem: $1 \mu \mathrm{g} \mathrm{ml}^{-1}$ ); 5 , PAe391. The arrow indicates the position of the presumed OprD2 protein. Molecular mass markers (in kDa) are shown in lane 1.

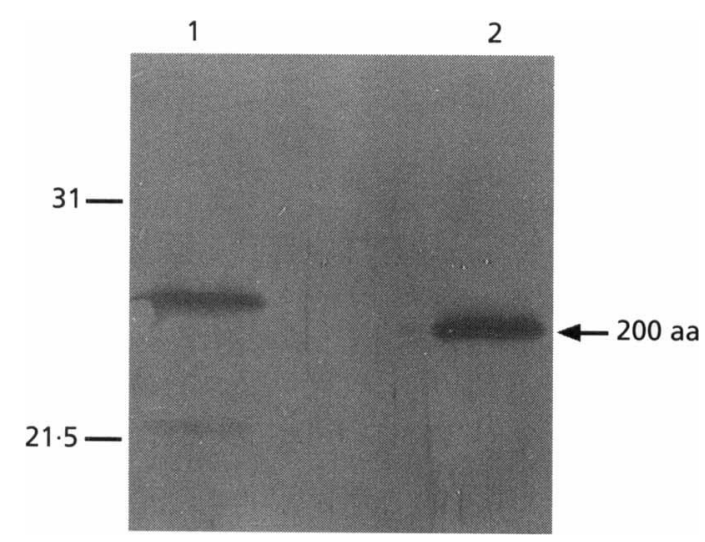

Fig. 5. Immunoblot of $A A C\left(6^{\prime}\right)-1 b_{10}$ (lane 1$)$ and $A A C\left(6^{\prime}\right)-1 b(200$ amino acids, lane 2) produced by HB101(pAZ505). The positions of molecular mass markers (in kDa) are indicated on the left.

from the aminoglycoside resistance gene was similar to corresponding sequences found adjacent to other AAC $\left(6^{\prime}\right)$-Ib genes (Tran Van Nhieu \& Collatz, 1987; Galimand et al., 1993), but less so to the 59 bp consensus sequence (Hall et al., 1991), while the 61 bp sequence downstream from the OXA-13 gene was similar to the corresponding sequence of OXA-7 (Scoulica et al., 1995)

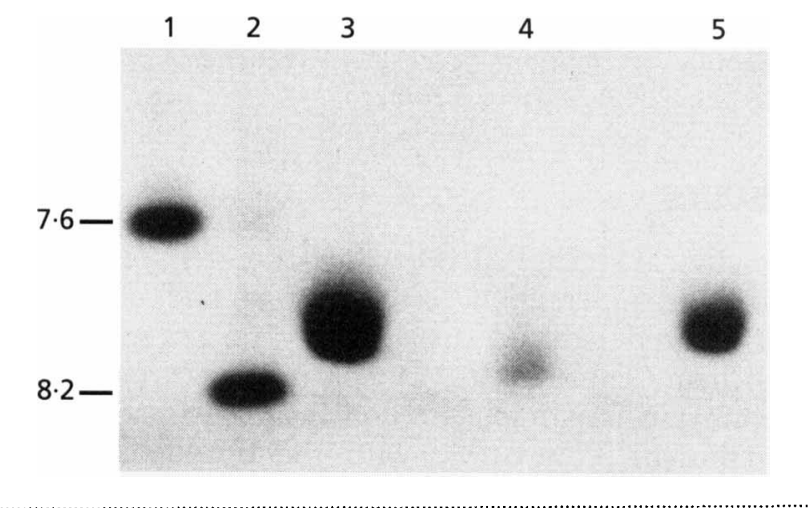

Fig. 6. Isoelectric focusing of OXA-13. Equal amounts of soluble proteins ( $\$ 100)$ from HB101(pAZ304) were focused, without (lane 3), or after preincubation with imipenem (lane 4), or meropenem (lane 5). $\beta$-Lactamase activity was revealed by overlay with nitrocefin. Isoelectric point standards were SHV-1 (pl 7.6, lane 1) and SHV-5 (pl 8.2, lane 2).

and also to the $59 \mathrm{bp}$ consensus sequence (Hall et al., 1991).

The nucleotide sequence of the $a a c\left(6^{\prime}\right)-I b$ gene was most similar to that carried on plasmid pAZ007 (Tran Van Nhieu \& Collatz, 1987), with the exception of the $5^{\prime}$ terminus, raising the question of the identity of the translation initiation codon. Using immunoblotting with anti-AAC $\left(6^{\prime}\right)$-Ib antibodies as described previously (Tran Van Nhieu et al., 1992), PAe391 was found to produce a cross-reactive protein with a slightly lower mobility than that of the pAZ007-encoded AAC $\left(6^{\prime}\right)-\mathrm{Ib}$, which is 200 amino acids in length (Fig. 5). The only start codon preceded by a putative ribosome-binding site and consistent with a protein longer than 200 amino acids appeared to be the A248TG codon (Fig. 2), the same codon that was previously determined experimentally to initiate translation of a different acetyltransferase gene (Wohlleben et al., 1989). The resulting AAC variant of 203 amino acids with a computed molecular mass of $22 \cdot 6 \mathrm{kDa}$ was named $\mathrm{AAC}\left(6^{\prime}\right)-\mathrm{Ib}_{10}$.

The second ORF coded for a protein of 266 amino acids of the OXA-type $\beta$-lactamases, showing $97 \%$ amino acid identity with both OXA-10 (Huovinen et al., 1988) and OXA-7 (Scoulica et al., 1995). It was a novel variant of this family and was named OXA-13. N-terminal analysis of the mature protein yielded the sequence SerSer-Ile-Thr-Glu-Asn-Thr-Ser-Trp. The deduced signal peptide was 19 amino acids in length and the computed molecular mass of the mature protein $27 \cdot 4 \mathrm{kDa}$.

\section{Properties of the $\beta$-lactamase OXA-13}

Isoelectric focusing of an $\$ 100$ preparation from HB101(pAZ304) revealed the production of a $\beta$-lactamase with a $\mathrm{pI}_{\text {app }}$ of 8.0 (Fig. 6, lane 3). Non-induced PAe391 produced this same OXA-13 enzyme, but after induction at mid-exponential-phase with imipenem at $5 \mu \mathrm{g} \mathrm{ml}^{-1}$, no OXA-13 activity was apparent, and only the in- 
Table 3. Kinetic constants of OXA-13

\begin{tabular}{|llrlrlrl|}
\hline & \multicolumn{8}{c|}{ Substrate $^{*}$} \\
\cline { 2 - 9 } & Cri & Pen G & Amp & Oxa & Ctx & Atm & Caz $\dagger$ \\
\hline Relative $V_{\max }(\%)$ & $100 \ddagger$ & 69 & 80 & 213 & 119 & 4 & - \\
$K_{\mathrm{m}}(\mu \mathrm{M})$ & 615 & 65 & 62 & 71 & 691 & 104 & - \\
Relative $V_{\max } / K_{\mathrm{m}}(\%)$ & $100 \$$ & 530 & 640 & 1840 & 105 & 24 & - \\
\hline
\end{tabular}

*Hydrolysis of: Cri, cephaloridine; Pen G, penicillin G; Amp, ampicillin; Oxa, oxacillin; Ctx, cefotaxime; Atm, aztreonam; Caz, ceftazidime.

† Hydrolysis of ceftazidime was detected, but kinetic parameters were not measurable.

₹Corresponds to $11.4 \mathrm{mmol} \mathrm{s}^{-1}$.

\Corresponds to $7 \mathrm{~s}^{-1}$.

ducible cephalosporinase, with a $\mathrm{pI}_{\mathrm{app}}$ of $8 \cdot 2$, was observed after isoelectric focusing (data not shown). The presence of OXA-13 was similarly masked when the $\mathrm{S} 100$ proteins from HB101(pAZ304) were incubated with imipenem prior to isoelectric focusing (Fig. 6, lane 4). Masking of the OXA-13 activity under these conditions was much less evident with meropenem (Fig. 6, lane 5).

Kinetic constants for OXA-13 produced by HB101(pAZ304) are shown in Table 3 . The $K_{\mathrm{m}}$ values of the three penicillins tested were similar, $(60-70 \mu \mathrm{M})$, and approximately ten times lower than those of cephaloridine and cefotaxime. The highest relative $V_{\max } / K_{\mathrm{m}}$ ratio was observed for oxacillin, which is in agreement with the molecular features of OXA-13, a class D $\beta$ lactamase closely related to OXA-10 (Ledent et al., 1993). OXA-13 was more efficient as a penicillinase than as a cephalosporinase, with rather high $K_{\mathrm{m}}$ values for those cephalosporins for which they could be determined, but was able to hydrolyse cefotaxime and ceftazidime as well as aztreonam. This should explain the incresase in the MICs of these antibiotics for the enzyme-producing $E$. coli (Table 2 ). Kinetic constants could not, however, be determined for ceftazidime, possibly because the $K_{\mathrm{m}}$ of this compound was much higher than the substrate concentrations that could be used under our experimental conditions.

In a disk diffusion test, imipenem showed inhibitor activity against OXA-13, as evidenced by increased zones of growth inhibition around disks containing $\beta$ lactams that can be hydrolysed by the enzyme, such as cefsulodin, and to some degree apparently also meropenem (Fig. 3). Meropenem and clavulanic acid displayed no inhibitor activity in this test (data not shown). The differences in inhibitor activities of the carbapenems could not be attributed to differences in affinity, since the $K_{i \text { app }}$ values of imipenem and meropenem, 11 and $16 \mathrm{nM}$, respectively, were found to be similar, while that of clavulanic acid was $54 \mu \mathrm{M}$.

The stability of the OXA-13: carbapenem complexes was estimated by determining the kinetics of enzyme

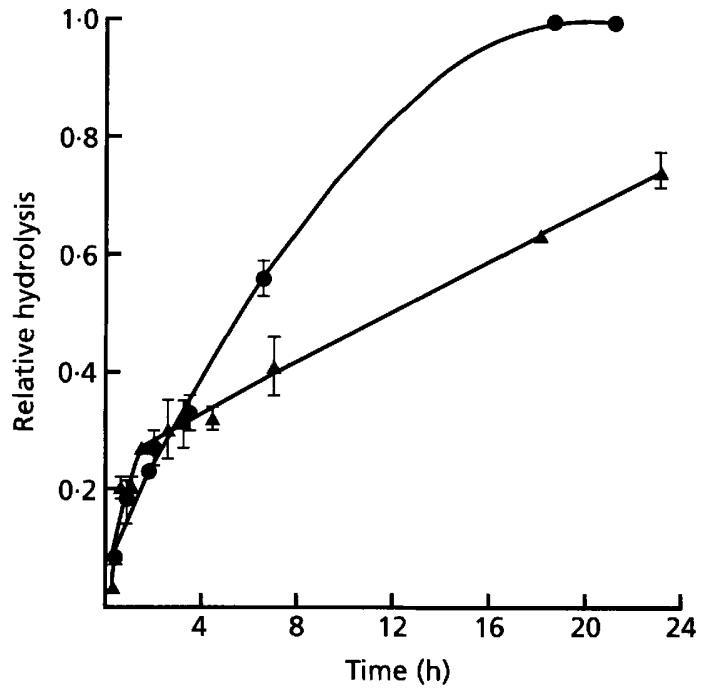

Fig. 7. OXA-13 reactivation kinetics. Enzyme:inhibitor complexes were isolated by gel filtration after preincubation of an $\$ 100$ sample from HB101(pAZ304) in the presence of $70 \mu \mathrm{M}$ of imipenem $(\boldsymbol{\Delta})$ or meropenem $(\boldsymbol{\theta})$ at $30^{\circ} \mathrm{C}$. A control sample was preincubated in the absence of inhibitor, but otherwise treated identically. Enzyme activity was measured with cephaloridine as the substrate and the activity in the control (58-72 $\mathrm{nmol} \mathrm{min}-1 \mathrm{mg}^{-1}$ at time zero) set at 1 at each time point. For details see Methods.

reactivation (Fig. 7). Under the conditions used, the rate of hydrolysis of cephaloridine was completely stable for $8 \mathrm{~h}$. It decreased to approximately $70 \%$ after $18 \mathrm{~h}$ and to approximately $50 \%$ after $24 \mathrm{~h}$. In agreement with the observation shown in Fig. 6, imipenem formed a very stable complex. About $30 \%$ of the enzyme remained inhibited after $24 \mathrm{~h}$ at $30^{\circ} \mathrm{C}$, following a biphasic course of recovery of enzyme activity with an initial rapid reactivation over $2 \mathrm{~h}$, and a much slower reactivation thereafter (Fig. 7). By contrast, the OXA-13: meropenem complex was less stable, with $100 \%$ of the $\beta$-lactamase activity regained after $18 \mathrm{~h}$ at a steady rate throughout. The apparent half-lives of the respective OXA-carba- 
penem complexes were estimated to be approximately 12 and $5 \mathrm{~h}$.

\section{DISCUSSION}

The susceptibility pattern of the clinical $P$. aeruginosa strain PAe391, with resistance to $\beta$-lactam antibiotics, aminoglycosides, sulfonamides and mercuric ions, raised the possibility that the resistance genes were carried by a Tn21-related transposable element, and nucleotide sequence analysis revealed that novel variants of an aminoglycoside acetyltransferase gene, aac $\left(6^{\prime}\right)$ $I b_{10}$, and of a $\beta$-lactamase gene, $b l a_{\mathrm{OXA}-13}$, were inserted in the form of cassettes in an integron structure. This integron appeared to be chromosome-borne, an apparently uncommon situation (Stokes \& Hall, 1989; Francia \& Garcia Lobo, 1996). Although its complete sequence has not been determined, it is likely that it also encodes the sulfonamide resistance determinant which was present in the cloned DNA fragment of pAZ301, a fragment with integron-typical endonuclease restriction sites (Fig. 1). The responsible gene, sull, is normally found in the $3^{\prime}$ conserved integron segment (Bissonnette \& Roy, 1992; Stokes \& Hall, 1989). The arrangement of an $a a c\left(6^{\prime}\right)-I b$ and a $b l a_{\mathrm{OxA}}$ gene within an integron does not seem to have been reported previously. However, in an arrangement somewhat similar to that observed on the cloned fragment of pAZ301, a segment of approximately 600 bp separated an $a a c\left(6^{\prime}\right)-I b$ from the $b l a_{\text {oxA-3 }}$ gene (Sanschagrin et al., 1995), incompatible with the length of the recombination site sequences typically found between the gene cassettes in integrons (Hall et al., 1991).

Comparative analysis by immunoblotting of the
AAC $\left(6^{\prime}\right)$-Ib produced by PAe391 revealed that it was slightly larger than the prototype enzyme of 200 amino acids (Fig. 5). Considering the genomic context of $a a c\left(6^{\prime}\right)-I b$ in PAe391, it appeared that the translation initiation codon was localized in the $5^{\prime}$ conserved segment of the integron, upstream from the recombination site named hs2 by Schmidt et al. (1989). An ATG codon preceded by a ribosome-binding site has been identified in that location in two aminoglycoside acetyltransferase genes, aac(3)-Ia (Wohlleben et al., 1989; Tenover et al., 1989) and aac(6')-Ib (Mabilat et al., 1992), which carry a 19 bp duplication adjacent to the recombination site (Fig. 8). It is likely that the same initiation codon is functional in PAe391, although the $\mathrm{N}$-terminal sequence of its $\mathrm{AAC}\left(6^{\prime}\right)-\mathrm{Ib}_{10}$, encoded by the $5^{\prime}$ conserved integron segment, is different from that of the other two acetyltransferases. One explanation for this difference could be a $21 \mathrm{bp}$ in-frame deletion covering part of the 19 bp duplication (Fig. 8). The Nterminal sequence of $\mathrm{AAC}\left(6^{\prime}\right)-\mathrm{Ib}_{10}$ in PAe391 might alternatively result from the deletion of two $G$ residues (positions 58 and 59 in Fig. 8) in an integron lacking the $19 \mathrm{bp}$ duplication. A different deletion affecting the $19 \mathrm{bp}$ duplication has been observed in the integron carried by pAT127, leaving no start codon in the proper reading frame in that region and resulting in the synthesis of an acetyltransferase thought to be shorter by approximately 30 amino acids (Galimand et al., 1993). Beyond the tenth amino acid, $\mathrm{AAC}\left(6^{\prime}\right)-\mathrm{Ib}_{10}$ was identical to the variant initially described (Tran Van Nhieu \& Collatz, 1987) and those referred to in Fig. 8, except for the two penultimate residues (cf. Fig. 2).

The second resistance gene cassette in the integron of PAe391 coded for an oxacillin-hydrolysing $\beta$-lactamase,
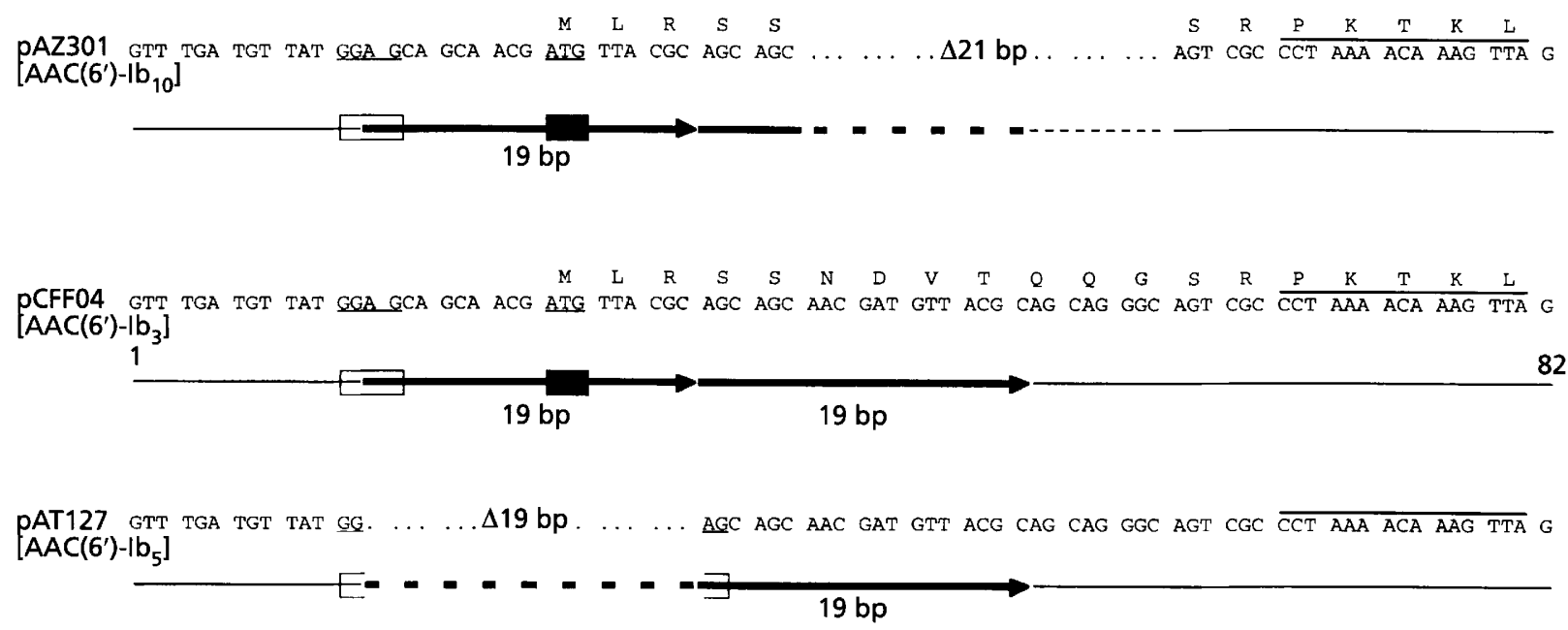

Fig. 8. Deduced N-terminal $A A C\left(6^{\prime}\right)$-lb sequences. The start codon on pCFF04 (Mabilat et al., 1992; positions 25-27 in this figure) was localized in the first of two $19 \mathrm{bp}$ direct repeat sequences at the $3^{\prime}$ extremity of the $5^{\prime}$ conserved integron segment of Tn21 by analogy with that determined previously for the aac(3)-la gene (Wohlleben et al., 1989). The corresponding codon on pAZ301 would remain in-frame after a 21 bp deletion, but would be eliminated by a 19 bp deletion on pAT127 described by Galimand et al. (1993). Open rectangles, putative ribosome-binding sites; filled rectangles, start codons. 
which was named OXA-13. OXA-type enzymes, less closely related to one another than the TEM- and SHVtype enzymes (Jacoby, 1994), have been assigned to four groups (Sanschagrin et al., 1995). OXA-13 is closest to the OXA-10-related group. It differs from OXA-7 (Scoulica et al., 1995) and OXA-10 (formerly PSE-2; Huovinen et al., 1988) in seven and eight amino acids, respectively, and from the extended-spectrum, ceftazidime-resistance-conferring $\beta$-lactamases of this group, OXA-11 (Hall et al., 1993), OXA-14 (Danel et al., 1995), OXA-13-1 (formerly OXA-13; Mugnier et al., 1994) and OXA-19 (P. Mugnier, I. Casin, \& E. Collatz, unpublished results), essentially in that it does not display the Gly-to-Asp change in position 157. Determination of the kinetic parameters of OXA-13 showed that it is a broad-spectum $\beta$-lactamase only moderately efficient against cephalosporins and aztreonam. This is in agreement with the moderate increase in the MICs of most $\beta$-lactams for PAe391. The property of hydrolysing the more recent penicillinase-resistant $\beta$ lactam antibiotics has previously been observed with OXA-10 (Bush et al., 1995; Hall et al., 1993; Ledent et al., 1993), which has $97 \%$ amino acid identity with OXA-13.

OXA-13 was efficiently inhibited by imipenem. This was suggested by the synergistic effect of the combination of imipenem with other $\beta$-lactam compounds, as seen from the MIC data (Table 2) and in the disk diffusion assay (Fig. 3). A similar effect was noted with OXA-10- and OXA-7-producing strains (data not shown). Used at a 64-fold lower concentration, imipenem was as efficient as clavulanic acid, for which a $K_{i \text { app }}$ of $54 \mu \mathrm{M}$ was found, in reducing the MICs of ceftazidime and aztreonam for E. coli. A stable association between OXA-13 and imipenem was substantiated by the isoelectric focusing results (Fig. 6, lane 4) and by the observation of an OXA-13:imipenem complex which dissociated only partially after as much as $24 \mathrm{~h}$ (Fig. 7). With the $K_{i a p p}$ values of imipenem and meropenem being similar, the apparent difference in stability of the OXA-13:imipenem and OXA-13:meropenem complexes (Fig. 7) is not easily explained. One possible explanation could be the existence of a branched pathway of substrate inactivation with a very low (and difficult to quantify) proportion of the enzyme involved in the hydrolysis branch. Using an undiluted enzyme preparation we indeed observed some steady state hydrolysis of meropenem, which appeared to be three- to fourfold greater than that of imipenem, which was marginal (data not shown).

Imipenem has been known for several years to act as an inhibitor of $\beta$-lactamases, including chromosome-encoded cephalosporinases of Gram-negative bacteria (Hashizume et al., 1984; Monks \& Waley, 1988; Nouda et al., 1992), TEM-type enzymes (Neu \& Labthavikul, 1982; Nouda et al., 1992) and oxacillinases (Toda et al., 1980). The inhibition of OXA-13 with imipenem seemed particularly stable, and more so than with meropenem (Figs 6, 7), although their apparent $K_{\mathbf{i}}$ values were similar.
Interest in imipenem as a $\beta$-lactamase inhibitor in $P$. aeruginosa is limited by its powerful activity as an inducer of the chromosome-encoded cephalosporinase (Livermore \& Yang, 1987). This limitation might be less important in strains such as PAe391 which do not synthesize the porin D2 responsible for preferential diffusion of imipenem (Trias \& Nikaido, 1990). Thus, imipenem, when used as an inhibitor, decreased the MICs of all $\beta$-lactams tested to levels four- to eightfold lower in PAe391 than in PAO38(pAZ309) (Table 2). The ability of OXA-10-related enzymes, whether of extended spectrum or not, to hydrolyse antibiotics such as aztreonam, cefotaxime or cefsulodin, in conjunction with its susceptibility to inhibition by imipenem, should aid in the detection of such enzymes in $P$. aeruginos $a$ and in their differentiation from other OXA-type enzymes and from class A $\beta$-lactamases.

\section{ACKNOWLEDGEMENTS}

This work was supported by grants from the Institut National de la Santé et de la Recherche Médicale (CRE 93063 and CRI 95061). We are grateful to A. Philippon for helpful discussions, to A. Coutrot for help with the immunoblotting experiments, to L. Gutmann for the gift of strain S17.1 and plasmid pNJR32, to G. Paul for the gift of OXA-10- and OXA-7producing strains, and to $\mathrm{C}$. Harcour for secretarial assistance.

\section{REFERENCES}

Birnboim, H. C. \& Doly, J. (1979). A rapid alkaline extraction procedure for screening recombinant plasmid DNA. Nucleic Acids Res 7, 1513-1523.

Bissonnette, L. \& Roy, P. H. (1992). Characterization of In0 of Pseudomonas aeruginosa plasmid pVS1, an ancestor of integrons of multiresistance plasmids and transposons of Gram-negative bacteria. J Bacteriol 174, 1248-1257.

Bush, K., Jacoby, G. A. \& Medeiros, A. A. (1995). A functional classification scheme for $\beta$-lactamases and its correlation with molecular structure. Antimicrob Agents Chemother 39, 12111233.

Cameron, F. H., Groot Obbink, D. J., Ackerman, V. P. \& Hall, R. M. (1986). Nucleotide sequence of $\operatorname{AAD}\left(2^{\prime \prime}\right)$ aminoglycoside adenyltransferase determinant $a a d B$. Evolutionary relationship of this region with those surrounding aadA in R538-1 and dbfrII in R388. Nucleic Acids Res 14, 8625-8635.

Danel, F., Hall, L. M. C., Gur, D. \& Livermore, D. M. (1995). OXA14 , another extended-spectrum variant of OXA-10 (PSE-2) $\beta$ lactamase from Pseudomonas aeruginosa. Antimicrob Agents Chemother 39, 1881-1884.

Francia, M. V. \& Garcia Lobo, J. M. (1996). Gene integration in the Escherichia coli chromosome mediated by Tn21 integrase (Int21). $J$ Bacteriol 178, 894-898.

Francia, M. V., de la Cruz, F. \& Garcia Lobo, J. M. (1993). Secondary sites for integration mediated by the Tn21 integrase. Mol Microbiol 10, 823-828.

Galimand, M., Lambert, T., Gerbaud, G. \& Courvalin, P. (1993). Characterization of the $a a c\left(6^{\prime}\right)-1 b$ gene encoding an aminoglycoside $6^{\prime}-\mathrm{N}$-acetyltransferase in Pseudomonas aeruginosa BM2656. Antimicrob Agents Chemother 37, 1456-1462.

Grinsted, J., De La Cruz, F. \& Schmitt, R. (1990). The Tn21 subgroup of bacterial transposable elements. Plasmid 24, 163-189. 
Hall, R. M. \& Collis, C. M. (1995). Mobile gene cassettes and integrons: capture and spread of genes by site-specific recombination. Mol Microbiol 15, 593-600.

Hall, R. M., Brookes, D. E. \& Stokes, H. W. (1991). Site-specific insertion of genes into integrons: role of the 59-base element and determination of the recombination cross-over point. Mol Microbiol 5, 1941-1959.

Hall, L. M. C., Livermore, D. M., Gur, D., Akova, M. \& Akalin, H. E. (1993). OXA-11, an extended-spectrum variant of OXA-10 (PSE-2) $\beta$-lactamase from Pseudomonas aeruginosa. Antimicrob Agents Chemother 37, 1637-1644.

Hashizume, T., Yamaguchi, A., Hirata, T. \& Sawai, T. (1984). Kinetic studies on the inhibition of Proteus vulgaris $\beta$-lactamase by imipenem. Antimicrob Agents Chemother 25, 149-151.

Huovinen, P., Huovinen, S. \& Jacoby, G. A. (1988). Sequence of PSE-2 $\beta$-lactamase. Antimicrob Agents Chemother 32, 134-136.

Jacoby, G. A. (1994). Genetics of extended-spectrum $\beta$-lactamases. Eur J Clin Microbiol Infect Dis 13 (Suppl. 1), 2-11.

Kado, C. I. \& Liu, S. T. (1981). Rapid procedure for detection and isolation of large and small plasmids. J Bacteriol 145, 1365-1373.

Laemmli, U. K. (1970). Cleavage of structural proteins during the assembly of the head of bacteriophage T4. Nature 277, 680-685.

Lafond, M., Couture, F., Vézina, G. \& Levesque, R. C. (1989). Evolutionary perspectives on multiresistance $\beta$-lactamase transposons. J Bacteriol 171, 6423-6429.

Ledent, P., Raquet, X., Joris, B., Van Beeumen, J. \& Frère, J. M. (1993). A comparative study of class-D $\beta$-lactamases. Biochem J 292, 555-562.

Lee, E. H., Collatz, E., Trias, J. \& Gutmann, L. (1992). Diffusion of $\beta$-lactam antibiotics into proteoliposomes reconstituted with outer membranes of isogenic imipenem-susceptible and -resistant strains of Enterobacter cloacae. J Gen Microbiol 138, 2347-2351.

Lévesque, C., Piché, L., Larose, C. \& Roy, P. H. (1995). PCR mapping of integrons reveals several novel combinations of resistance genes. Antimicrob Agents Chemother 39, 185-191.

Livermore, D. M. (1991). $\beta$-Lactamases of Pseudomonas aeruginosa. In Antibiotics and Chemotherapy, vol. 44, Pseudomonas aeruginosa in Human Diseases, pp. 215-220. Edited by J. Y. Homma, H. Tanimoto, I. A. Holder, N. Hoiby \& G. Döring. Basel: Karger.

Livermore, D. M. (1995). $\beta$-Lactamases in laboratory and clinical resistance. Clin Microbiol Rev 8, 557-584.

Livermore, D. \& Yang, Y. J. (1987). $\beta$-Lactamase lability and inducer power of newer $\beta$-lactam antibiotics in relation to their activity against $\beta$-lactamase-inducibility mutants of Pseudomonas aeruginosa. J Infect Dis 155, 775-782.

Mabilat, C., Vital, J. L., Goussard, S. \& Courvalin, P. (1992). A new example of physical linkage between $\operatorname{Tn} 1$ and $\operatorname{Tn} 21$ : the antibiotic multiple-resistance region of plasmid pCFF04 encoding extendedspectrum $\beta$-lactamase TEM-3. Mol Gen Genet 235, 113-121.

Monks, J. \& Waley, S. G. (1988). Imipenem as substrate and inhibitor of $\beta$-lactamases. Biochem J 253, 323-328.

Mugnier, P., Podglajen, I., Gutmann, L. \& Collatz, E. (1994). Cloning and nucleotide sequence analysis of two Pseudomonas aeruginosa genes encoding the novel OXA-type $\beta$-lactamase variants OXA-12 and OXA-13, susceptible to inhibition by imipenem. In Program and Abstracts of the 34th Interscience Conference on Antimicrobial Agents and Chemotherapy, abstract C98, p. 139. Washington, DC: American Society for Microbiology.

Neu, H. C. \& Labthavikul, P. (1982). Comparative in vitro activity of $N$-formimidoyl thienamycin against Gram-positive and Gramnegative aerobic and anaerobic species and its $\beta$-lactamase stability. Antimicrob Agents Chemother 21, 180-187.

Nouda, H., Harabe, E. T., Sumita, Y., Okuda, T. \& Fukasawa, M. (1992). Beta-lactamase stability and inhibitory activity of meropenem combined with a potent antibacterial activity. Chemotherapy 38, 218-224.

Ouellette, M. \& Roy, P. H. (1987). Homology of ORFs from Tn2603 and from R46 to site-specific recombinases. Nucleic Acids Res 15, 10055-10056.

Paulsen, I. T., Littlejohn, T., Rädström, P., Sundström, L., Sköld, O., Swedberg, G. \& Skurray, R. A. (1993). The 3' conserved segment of integrons contains a gene associated with multidrug resistance to antiseptics and disinfectants. Antimicrob Agents Chemother 37, 761-768.

Pemberton, J. M. \& Holloway, B. W. (1972). Chromosome mapping in Pseudomonas aeruginosa. Genet Res 19, 251-260.

Robillard, N. J. (1990). Broad-host-range gyrase A gene probe. Antimicrob Agents Chemother 34, 1889-1894.

Sanschagrin, F., Couture, F. \& Levesque, R. C. (1995). Primary structure of OXA-3 and phylogeny of oxacillin-hydrolyzing class D $\beta$-lactamases. Antimicrob Agents Chemother 39, 887-893.

Schmidt, F. R. J., Nücken, E. J. \& Henschke, R. B. (1989). Structure and function of hot spots providing signals for site-directed specific recombination and gene expression in Tn 21 transposons. Mol Microbiol 3, 1545-1555.

Scoulica, E., Aransay, A. \& Tselentis, Y. (1995). Molecular characterization of the OXA-7 $\beta$-lactamase gene. Antimicrob Agents Chemother 39, 1379-1382.

Seifert, S. H., So, M. \& Heffron, F. (1986). Shuttle mutagenesis : a method of introducing transposons into transformable organisms. In Genetic Engineering, Principles and Methods, vol. 8, pp. 123-134. Edited by J. K. Setlow \& A. Hollaender. New York: Plenum.

Shaw, K. J., Rather, P. N., Hare, R. S. \& Miller, G. H. (1993). Molecular genetics of aminoglycoside resistance genes and familial relationships of the aminoglycoside-modifying enzymes. Microbiol Rev 57, 138-163.

Stokes, H. W. \& Hall, R. M. (1989). A novel family of potentially mobile DNA elements encoding site-specific gene-integration functions: integrons. Mol Microbiol 3, 1669-1683.

Takahashi, S. \& Nagano, Y. (1984). Rapid procedure for isolation of plasmid DNA and application to epidemiological analysis. $J$ Clin Microbiol 20, 608-613.

Tenover, F. C., Phillips, K. L., Gilbert, T., Lockhart, P., O'Hara, P. J. \& Plorde, J. J. (1989). Development of a DNA probe from the deoxyribonucleotide sequence of a 3-N-aminoglycoside acetyltransferase [AAC(3)-I] resistance gene. Antimicrob Agents Chemother 33, 551-559.

Thompson, R. (1986). R plasmid transfer. J Antimicrob Chemother 18 (Suppl. C), 13-23.

Toda, M., Sato, K., Nakazawa, H., Inoue, L. \& Mitsuhashi, S. (1980). Effect of $N$-formimidoyl thienamycin (MK0787) on $\beta$ lactamases and activity against $\beta$-lactamase-producing strains. Antimicrob Agent Chemother 18, 837-838.

Tran Van Nhieu, G. \& Collatz, E. (1987). Primary structure of an aminoglycoside $6^{\prime}-N$-acetyltransferase, $\mathrm{AAC}\left(6^{\prime}\right)-4$, fused in vivo with the signal peptide of the Tn3-encoded $\beta$-lactamase. $J$ Bacteriol 169, 5708-5714.

Tran Van Nhieu, G., Bordon, F. \& Collatz, E. (1992). Incidence of an aminoglycoside $6^{\prime}-N$-acetyltransferase $\mathrm{AAC}\left(6^{\prime}\right)-\mathrm{Ib}$, in amikacin-resistant clinical isolates of Gram-negative bacilli, as 
determined by DNA-DNA hybridisation and immunoblotting. $J$ Med Microbiol 36, 83-88.

Trias, J. \& Nikaido, H. (1990). Outer membrane protein D2 catalyses facilitated diffusion of carbapenems and penems through the outer membrane of Pseudomonas aeruginosa. Antimicrob Agents Chemother 34, 52-57.

Wohlleben, W., Arnold, W., Bissonnette, L., Pelletier, A. Tanguay, A., Roy, P. H., Gamboa, G. C., Barry, G. F., Aubert, E., Davies, J. \& Kagan, S. A. (1989). On the evolution of Tn21-like multiresistance transposons: sequence analysis of the gene
(aacC1) for gentamicin acetyltransferase-3-I (AAC(3)-I), another member of the Tn21-based expression cassette. Mol Gen Genet 217, 202-208.

Zhou, X. Y., Kitzis, M.-D. \& Gutmann, L. (1993). Role of cephalosporinase in carbapenem resistance of clinical isolates of Pseudomonas aeruginosa. Antimicrob Agents Chemother 37, $1387-1389$.

Received 23 July 1997; revised 13 November 1997; accepted 21 November 1997. 